\title{
Analyses of Early Sunspot Records by Jean Tarde (1615 - 1617) and Jan Smogulecki (1621 - 1625)
}

\author{
V.M.S. Carrasco ${ }^{1,2}$ (D) M.C. Gallego ${ }^{1,2}$ (D) J. Villalba Álvarez ${ }^{3} \cdot$ J.M. Vaquero ${ }^{2,4}$ (D) \\ H. Hayakawa ${ }^{5,6,7,8}$
}

Received: 5 March 2021 / Accepted: 23 September 2021 / Published online: 22 November 2021

(c) The Author(s) 2021

\begin{abstract}
Jean Tarde and Jan Smogulecki carried out sunspot observations in the 1610s and 1620s at the dawn of the telescopic era. We analysed their original observational records to revise their sunspot-group numbers in the existing database. In this study, we provide a new counting as a basis for future scientific discussions. Furthermore, we compared Smogulecki's sunspot observations with those of Scheiner and Schönberger on the same observation days. We also detected a big sunspot group on 2 - 3 February 1622 in Smogulecki's sunspot drawings and estimated its area to be approximately 1600 millionths of the solar disc. In addition, we measured the sunspot positions in Tarde's and Smogulecki's sunspot drawings to construct a butterfly diagram for this early period.
\end{abstract}

Keywords Solar cycle, observations $\cdot$ Sunspots, statistics

\section{Introduction}

Sunspots have been observed for several millennia, although they started to be more systematically recorded since 1610, after the use of the telescope as an astronomical instrument (Yau and Stephenson, 1988; Vaquero and Vázquez, 2009; Hayakawa et al., 2017; Willis et al., 2018). The number of sunspot groups and individual sunspots observed on the solar

V.M.S. Carrasco

vmscarrasco@unex.es

1 Departamento de Física, Universidad de Extremadura, 06006 Badajoz, Spain

2 Instituto Universitario de Investigación del Agua, Cambio Climático y Sostenibilidad (IACYS), Universidad de Extremadura, 06006 Badajoz, Spain

3 Departamento de Ciencias de la Antigüedad, Universidad de Extremadura, 10071 Cáceres, Spain

4 Departamento de Física, Universidad de Extremadura, 06800 Mérida, Spain

5 Institute for Advanced Researches, Nagoya University, Nagoya, 4648601, Japan

6 Institute for Space-Earth Environmental Research, Nagoya University, Nagoya, 4648601, Japan

7 UK Solar System Data Centre, Space Physics and Operations Division, RAL Space, Science and Technology Facilities Council, Rutherford Appleton Laboratory, Harwell Oxford, Didcot, Oxfordshire, OX110QX, UK

8 Nishina Centre, Riken, Wako, 3510198, Japan 
disc were used to calculate the indices of the relative sunspot number and group sunspot number (Hoyt and Schatten, 1998; Clette and Lefèvre, 2016). These indices, derived from their counting, have been extensively used to characterise long-term solar activity, as they have been constructed from direct solar observations for the last four centuries. Recent studies have detected some problems with these sunspot-number indices (Clette et al., 2014). This was also the case with their background database (Hoyt and Schatten, 1998), which has been significantly revised and updated based on the original records (Vaquero et al., 2016). Currently, there is an ongoing global effort to address these problems and recalibrate the different sunspot-number indices (Muñoz-Jaramillo and Vaquero, 2019).

Harriot recorded the first known sunspot observations using a telescope on 18 December 1610 (Arlt and Vaquero, 2020; Vokhmyanin, Arlt, and Zolotova, 2020). In the dawn of the telescopic era, Scheiner and Galileo were two of the most important sunspot observers and antagonists of a famous historical debate on the nature of sunspots (Galilei and Scheiner, 2010). Other outstanding sunspot observers at the time were Malapert, Mögling, Tarde, and Smogulecki. Recently, some studies have analysed the earliest telescopic sunspot records and provided new information on the solar activity that occurred at that time. These studies also detected significant errors in the number of sunspot groups included in both the Hoyt and Schatten (1998) database and the most recently revised collection of sunspotgroup numbers by Vaquero et al. (2016) (hereafter V16). For example, Vokhmyanin, Arlt, and Zolotova $(2020,2021)$ studied the group numbers, latitudes, and areas of the original records of Harriot, Cigoli, Galileo, Cologna, Scheiner, and Colonna. Carrasco, Gallego, and Vaquero (2020) showed a significant number of observations made by Galileo and Scheiner in the 1610s that had been missed in V16. These authors also detected a change in the observation method carried out by Galileo (from observations through a telescope to the projection method) that influenced the number of groups recorded by him before and after this change. Neuhäuser and Neuhäuser (2016) revised early sunspot records made by Marius, Saxonius, Malapert, and other sunspot observers at the time. Carrasco et al. (2019) also analysed the sunspot observations made by Malapert for the period 1618-1626, obtaining a greater solar-activity level from these records than previously known. Hayakawa et al. (2021) consulted the original manuscript of Mögling's sunspot observations and derived his sunspot-group number and sunspot positions for the period 1626-1629. Arlt et al. (2016) calculated the areas, latitudes, and tilt angles from sunspot drawings recorded by Scheiner in his book Rosa Ursina (Scheiner, 1630); further, Vokhmyanin and Zolotova (2018a,b) determined the group numbers, positions, and areas from Galileo's and Gassendi's observations. All of these recent studies have allowed us to improve our knowledge of solar activity at the dawn of the telescopic era. However, further studies are required because the observational coverage of sunspot observations in the earliest period of the telescopic era is still scarce (Muñoz-Jaramillo and Vaquero, 2019).

In this context, we consulted Tarde's and Smogulecki's original Latin texts describing their sunspot records. Thus, we detected significant problems in the existing number of sunspot groups assigned to Tarde and Smogulecki in V16. The main objectives of the present work are: i) to provide a new group counting as a basis for future scientific discussions on the sunspot-group number, and ii) to calculate the sunspot latitudes recorded in Tarde's and Smogulecki's drawings. The remainder of this article is organised as follows: Section 2 includes biographical details about Tarde and Smogulecki that are relevant for interpreting their sunspot records. Section 3 presents our analyses and discussion of the number of sunspot groups. Section 4 shows the butterfly diagram obtained from the sunspot positions measured and computed from their drawings. Finally, Section 5 presents the main conclusions of this study. 


\section{Jean Tarde and Jan Smogulecki: Two Jesuit Sunspot Observers}

Jean Tarde $(1651-1636)$ was born in La Roque-Gageac (France; $\left.44^{\circ} 49^{\prime} \mathrm{N}, 1^{\circ} 11^{\prime} \mathrm{E}\right)$. Tarde earned his doctorate in law at the University of Cahors and continued his studies at the University of Paris (Saridakis, 2014). He held different religious positions throughout his life. He was ordained as a priest and moved to the parish of Carves. Later, he was promoted to canon theologian of Sarlat's cathedral, and then the bishop of Sarlat appointed him vicar general in 1594. Moreover, Tarde became a member of the Conseil du Roi (Dujarric-Descombes, 1971). Regarding his scientific career, he carried out studies in several disciplines, including mathematics, physics, and geography (Baumgartner, 1987). Tarde was interested in sunspots and was in contact with contemporary astronomers such as Galileo and Grünberger. In fact, Tarde visited them in Italy in 1614 . Thereafter, he returned to Sarlat $\left(44^{\circ} 53^{\prime} \mathrm{N}, 1^{\circ} 13^{\prime} \mathrm{E}\right)$ in 1615 and constructed a small observatory. His main scientific work was on sunspots. Tarde published his study on sunspots in the book Borbonia Sidera in Latin (Tarde, 1620) and its French translation in Les astres de Borbon (Tarde, 1627).

Jan Smogulecki (1610 - 1656) was born in Kraków (Poland; 5003’ N, 1956' E) (Kosibowiez, 1929; Witkowska, 2009; Roegel, 2011). He studied mathematics and astronomy in Freiburg and philosophy and law in Italy. When he returned to Poland around 1630, he was elected as mayor of Nakło and a local parliament member. In 1636, he joined the Jesuit order, studied theology in Kraków, and was ordained in Rome in 1641. He declared his intention to be a missionary and was sent to China in 1644 . He learned the Chinese language and customs and taught astronomy and mathematics in China. Smogulecki introduced, for the first time in China, the calculation of logarithms to his students. Spreading his fame, he was invited to the Chinese Imperial Court in Beijing. Shortly after this, Smogulecki requested permission to leave the Chinese imperial court to continue his missionary travels. Regarding sunspot observations, he started to observe sunspots at Freiburg $\left(48^{\circ} 00^{\prime} \mathrm{N}, 7^{\circ} 51^{\prime} \mathrm{E}\right)$ when he was only 11 years old in 1621 until the year 1625. Then, under the supervision of his mentor, Georg Schönberger, he published his work on sunspots Sol illustratus (Smogulecki, 1626).

\section{Sunspot Records: Analysis and Discussion}

\subsection{Tarde and Smogulecki's Sunspot Observations}

Tarde (1620) published his sunspot observations for the period 1615-1617 in Borbonia Sidera. In this book, Tarde published six sunspot drawings and textual reports to present his observations. One of them includes all the sunspot groups observed by Tarde on 25 August 1615. The other five drawings include a selection of sunspots among all those observed by Tarde to show some paths of sunspots crossing the solar disc. Two examples are presented in Figure 1 (top panel). Tarde indicated the solar disc orientations by letters A (centre), B (east), $\mathrm{C}$ (west), $\mathrm{F}$ (north), and $\mathrm{G}$ (south). The letters $\mathrm{D}$ and $\mathrm{E}$ represent the initial and final points of the path followed by each sunspot, and H, I, K, L, and M are letters assigned to the five sunspots that were depicted (Tarde, 1620, p. 32). The numbers included in these drawings indicate the day of the month when the sunspots were observed. The textual descriptions of the drawings were limited to the interval when each sunspot was observed. Tarde probably used the projection method to observe sunspots, as he himself explicitly described it (Tarde, 1620, p. 3). However, we could not find specific details about the observational method nor the sizes of Tarde's telescopes used in his observations. 


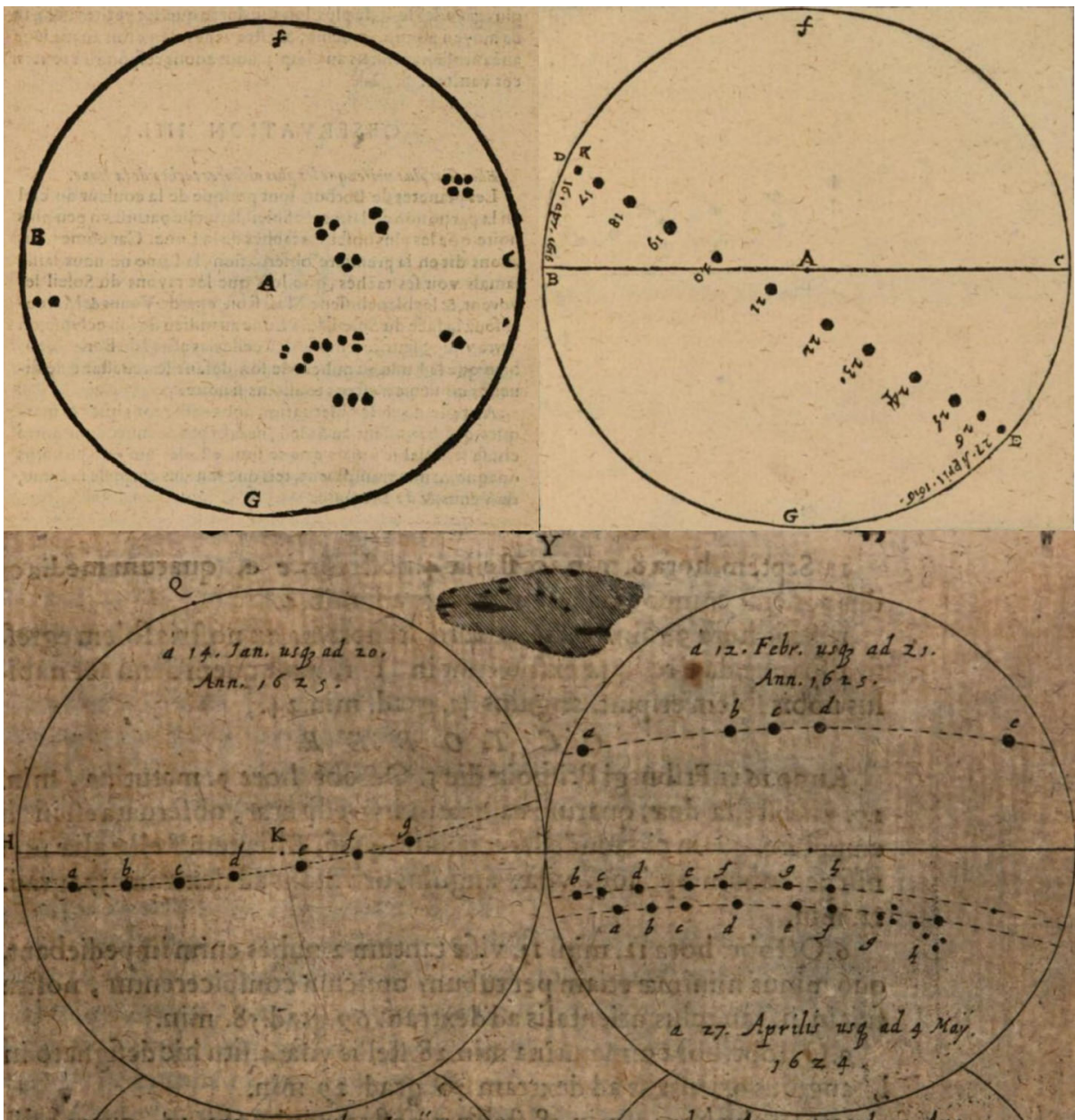

Figure 1 (Top panel) Sunspot groups recorded by Tarde on 25 August 1615 (top-left panel) and for the period 16-27 April 1616 (top-right panel) [Source: Tarde, 1620, p. 24 and 35]. (Bottom panel) Sunspot groups recorded by Smogulecki for the periods 14-20 January 1625 (bottom-left panel) and 27 April to 4 May 1624 and 12-21 February 1625 (bottom-right panel). The great sunspot "Y" depicted between both drawings was observed by Smogulecki on 2 February 1622 [Source: Smogulecki, 1626, p. 45].

Smogulecki also recorded sunspot drawings and textual reports to describe his observations. In his drawings, he recorded the groups to show their paths on the solar disc. Sometimes, he also recorded a selection of groups based on his observations. Figure 1 (bottom panel) shows two examples of Smogulecki's sunspot drawings. Smogulecki used black dots to draw the position of the sunspots on the solar disc and different letters to indicate their observation dates ordered chronologically. He also wrote down the observational period in each drawing and depicted the Ecliptic using a horizontal black line. Unlike Tarde, Smogulecki provides more details in his textual reports. The number of individual sunspots observed by Smogulecki on each observation day is indicated in his textual reports. Moreover, the number of groups can also be obtained because Smogulecki provides information on the distribution of sunspots on the solar disc not indicated in the sunspot drawings. However, their 
interpretation is sometimes challenging, because Smogulecki used the term "star" to design both individual sunspots and sunspot groups. For example, on 22 August 1625, the following observation was made (Smogulecki, 1626, p. 43): "(English translation) 22 August. Two stars. That above the Ecliptic was composed by many." We also detected some discrepancies between the observational period indicated in one of his drawings and the information recorded in the textual report, namely, in the middle-left of his drawings, Smogulecki indicated that the observation period of the sunspot "a" located in the northern hemisphere started on 30 May 1625 (Smogulecki, 1626, p. 45). However, in the annotations, he wrote that sunspot "a" (in the northern hemisphere) was observed for the first time on 1 June 1625, such as another sunspot recorded by Smogulecki in the southern hemisphere also named sunspot "a". Moreover, Smogulecki (1626, p. 47) indicated that he had an optimal tube of eight spans in length (approximately $1.8 \mathrm{~m}$, see Cardarelli, 2003), whereas we could not find any information regarding his observation methods. Smogulecki indicated that he made many more sunspot observations in other months and years. Nevertheless, he only published a part of them in Sol illustratus. One of the reasons for this was that it was enough for his purpose, and moreover, as indicated by him, a complete work on sunspots was about to be published in Rome (he probably referred to Rosa Ursina by Christoph Scheiner) (see Smogulecki, 1626, p. 47).

Tarde and Smogulecki explained some facts related to sunspots from their observational experience. According to Tarde: i) sometimes, only one sunspot can be seen on the Sun, and sometimes multiple sunspots can be seen (Tarde indicates that he counted 30 spots on 25 August 1615); however, there are no sunspots on the Sun for many days (Tarde pointed out that no sunspots appeared on the Sun during an entire month, but unfortunately he did not specify when it occurred); ii) it is possible that some sunspots can return to the solar disc after rotating on the other solar hemisphere (with different shapes), and they can be used to describe periodic motions that had not been analysed yet; iii) sunspots are not clouds or something similar but "stars" composed of opaque and non-transparent matter; iv) many sunspots are surrounded by filaments that are partly whitish and blackish; and v) these sunspots describe a uniform motion in a straight line, parallel to the Ecliptic and from the East to the West. Some of the interesting conclusions provided by Smogulecki that he deduced from his observations were the following: i) sunspots take around 12-14 days to cross the solar disc and move regularly and circularly, slower in motion when next to the limbs and faster around the disc centre, where they also seem bigger; ii) sunspots furthest from the Ecliptic cross the solar disc faster than those located close to the Ecliptic; iii) the path crossing the solar disc is not parallel to the Ecliptic, as assumed by some observers; iv) very few sunspots are perfectly round and they frequently have irregular shapes; v) the outline of almost all sunspots is a duller black than in the centre, and vi) some sunspots have a size equivalent to the Earth's radius (note that Smogulecki underestimated the relative size of the Sun with respect to the Earth since he recorded that the Sun diameter was equivalent to around only eleven Earth radii).

We now know that some of these conclusions were erroneous. However, despite this and their thought that sunspots were "stars" or "planets" orbiting the Sun, these astronomers demonstrated themselves to be rigorous observers, recording everything that they observed. The English translations from the original Latin texts of the reports made by Tarde and Smogulecki can be consulted on the website of the Historical Archive of Sunspot Observation (haso.unex.es). 


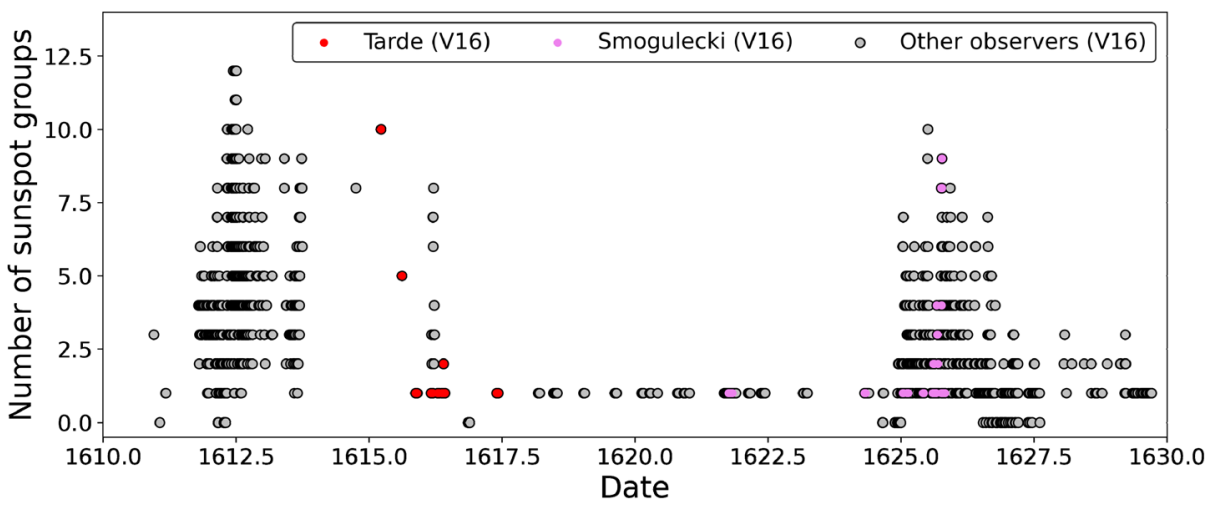

Figure 2 Daily number of groups included in V16 regarding all the observers for the period 1610-1629 (grey dots). Sunspot observations according to Tarde and Smogulecki are represented by red and violet, respectively.

\subsection{Sunspot Group Numbers}

Tarde and Smogulecki's sunspot records were previously analysed by Wolf (1859a, 1859b) and Hoyt and Schatten (1998) and then incorporated into the revised database of V16 without any change. In the latest database, the number of observational days assigned to Tarde is 69 for the period 25 March 1615-6 June 1617 and that for Smogulecki is 82 for the period 5 October $1621-1$ November 1625. Thus, Tarde's sunspot observations are located in the declining phase of the first solar cycle of the telescopic era and those from Smogulecki in the rising phase and the maximum of the second solar cycle. Figure 2 shows these records. Although we acknowledge that these are not a significant number of observations, Tarde and Smogulecki were two of the most active sunspot observers of their time. In fact, Tarde was the most active observer regarding his observation interval, followed by Saxonius (12 records) and Scheiner (5 records). Moreover, no other astronomers carried out observations on any of Tarde's observational days. In the case of Smogulecki, he was the second most active sunspot observer during his observing period. Only Scheiner recorded observations over more days in this interval ( 372 records). The other astronomers who made sunspot observations during this observation period were Malapert (17 records) and Hortensius ( 2 records) (V16; Hayakawa et al., 2021). Smogulecki was the only observer with records on 24 of his observation days. This is approximately $30 \%$ of all observations made by Smogulecki according to V16 (82 observation days).

We detected significant problems in the existing number of sunspot groups assigned to Tarde and Smogulecki in V16. Regarding Tarde's sunspot observations, one group is assigned to Tarde in V16 for each day in the periods 17-27 November 1615, 3-14 March 1616, 16-27 April 1616, 17 May - 6 June 1616, and 27 May - 6 June 1617, except on 27 and 28 May 1616, when two groups were assigned. These observations are included in five of Tarde's sunspot drawings, where he recorded one group for each date (Tarde, 1620, pp. 33 and $35-37$ ). The five sunspot groups represented in Tarde's five drawings were selected by Tarde from all the sunspot groups that he observed to explain his sunspot observations (see Tarde, 1620, p. 32). Therefore, Tarde's descriptions indicated that not all the observed sunspot groups on those observation days could have been recorded in the drawings. Tarde (1620, p. 37) only indicated in the drawing for the period 27 May -6 June 1617 that the sunspot group represented in that drawing was the only one observed on the Sun during 
those days. Therefore, the number of groups for 27 and 28 May 1616 should be corrected in future versions of the sunspot-group number database and those for the periods 17-27 November 1615, 3-14 March 1616, 16 - 27 April 1616, and 17 May - 6 June 1616 should be removed, as they only indicate the lower limit of the sunspot-group number for those dates. Regarding Tarde's sunspot drawing on 25 August 1615 (Tarde, 1620, p. 24), there are two observations in V16 assigned to Tarde related to this record. One of them includes a misinterpretation of the date of observation because ten groups were recorded by Tarde on 25 March 1615 (i.e. just five months before the real date of observation: 25 August 1615). Thus, this record should be removed from the database as well. The other record indicates that five groups were observed by Tarde on 25 August 1615. Unlike V16, we counted nine different sunspot groups for that day (Figure 1, top-left panel).

In the case of Smogulecki, the most significant problem detected was related to the number of groups observed by Smogulecki in the period 5-11 October 1625 (up to eight and nine groups in V16). Regarding all of the observers in V16, the second highest number of sunspot groups recorded during the second solar cycle of the telescopic era (in the 1620s) was nine groups by Smogulecki (the highest was ten groups observed by Scheiner on 4 July 1625). First, it seems that V16 misinterpreted the observational year of these records as 1625 , unlike the actual observation year of 1621. In addition, the number of sunspot groups assigned to Smogulecki in V16 for those wrong dates was actually the number of individual sunspots. Therefore, there were two groups on 5 and 6 October. Subsequently, only one sunspot group was recorded on 9, 10, and 11 October. Furthermore, Smogulecki did not record his sunspot observations on 7, 8, and 12 October 1621, unlike what was described in V16.

We found five days of Smogulecki's sunspot observations (2 and 3 November 1621 and 2, 3, and 12 February 1622) that were overlooked in V16, whereas we found nothing for Tarde's sunspot observations. In contrast to V16, we counted a different number of sunspot groups in one record for Tarde (25 August 1615) and discarded 57 days of Tarde's records, where it is not possible to know the real number of the observed sunspot groups. Regarding Smogulecki's data, we removed 18 days of the misinterpreted observations included in V16, because Smogulecki did not provide any information on sunspots on those dates. Moreover, we corrected the number of groups determined for the other 25 days. It was not possible to determine the number of groups on 17 observation days because of a lack of information. Therefore, the revised numbers of observation days for Tarde and Smogulecki are 12 and 52 , respectively. This implies a decrease of 57 and 30 observation days with respect to the total observation days assigned to Tarde and Smogulecki in V16, respectively. Figure 3 (top panel) shows the new group counting performed in this study and Table 1 lists the differences between the sunspot group counting made in this work and that in V16.

Carrasco et al. (2021) have recently revised the sunspot observations recorded by Scheiner $(1630,1651)$ in his books Rosa Ursina and Prodomus for the period 1611-1632 correcting significant problems in the number of groups related to those observations in V16. Figure 3 (bottom panel) combines the new counting method developed in this work with those of Carrasco et al. (2021) and Hayakawa et al. (2021), in addition to the records included in V16 for the period 1610 - 1632. The group counting obtained in this work from Smogulecki data is compatible with the values of the number of groups shown by Carrasco et al. (2021) for the rising phase of the 1620 s solar cycle.

The average number of groups per day recorded by Smogulecki counted in this study (1.9) was significantly greater than that from V16 (1.3) on the same observation days. Moreover, we can compare some of Smogulecki's observations against other contemporary astronomers' records on the same dates. Smogulecki and Scheiner observed the Sun on the 
Table 1 Differences between the sunspot-group counting in this work and that in V16. The first column indicates the observation period or date, the second column gives information on the astronomer (Tarde TAR, Smogulecki - SMO) responsible for the observation, the third and fourth columns provide the number of groups according to V16 and this work and the fifth column includes the explanation of the differences in the number of groups between this work and V16. The two final rows contain the number of observation days assigned to Tarde and Smogulecki in V16 and, in brackets, from this new counting.

\begin{tabular}{|c|c|c|c|c|}
\hline Date & Observer & $\begin{array}{l}\text { Groups } \\
\text { (V16) }\end{array}$ & $\begin{array}{l}\text { Groups } \\
\text { (this work) }\end{array}$ & Comments \\
\hline 25 Mar 1615 & TAR & 10 & - & $\begin{array}{l}\text { Misinterpretation of the observation } \\
\text { day in V16 }\end{array}$ \\
\hline 15 Aug 1615 & TAR & 5 & 9 & $\begin{array}{l}\text { Underestimation of the number of } \\
\text { groups in V16 }\end{array}$ \\
\hline $17-27$ Nov 1615 & TAR & 1 & - & $\begin{array}{l}\text { The value in V16 is a lower limit, } \\
\text { probably not the real number of } \\
\text { groups }\end{array}$ \\
\hline 3-14 Mar 1616 & TAR & 1 & - & $\begin{array}{l}\text { The value in V16 is a lower limit, } \\
\text { probably not the real number of } \\
\text { groups }\end{array}$ \\
\hline 16-27 Apr 1616 & TAR & 1 & - & $\begin{array}{l}\text { The value in V16 is a lower limit, } \\
\text { probably not the real number of } \\
\text { groups }\end{array}$ \\
\hline 17-26 May 1616 & TAR & 1 & - & $\begin{array}{l}\text { The value in V16 is a lower limit, } \\
\text { probably not the real number of } \\
\text { groups }\end{array}$ \\
\hline 27-28 May 1616 & TAR & 2 & - & $\begin{array}{l}\text { Misinterpretation both in the } \\
\text { observation days and the number of } \\
\text { groups in V16 }\end{array}$ \\
\hline 29 May to 6 June 1616 & TAR & 1 & - & $\begin{array}{l}\text { Misinterpretation of observation } \\
\text { days in V16 }\end{array}$ \\
\hline $5,6,13,14$ Oct 1621 & SMO & 1 & 2 & $\begin{array}{l}\text { Misinterpretation of the number of } \\
\text { groups in V16 }\end{array}$ \\
\hline $7,8,12$ Oct 1621 & SMO & 1 & - & $\begin{array}{l}\text { Misinterpretation of observation } \\
\text { days in V16 }\end{array}$ \\
\hline 15 Oct 1621 & SMO & 1 & - & $\begin{array}{l}\text { Not possible to count the real } \\
\text { number of groups }\end{array}$ \\
\hline $2-3$ Feb 1622 & SMO & - & 1 & $\begin{array}{l}\text { Observation days not included in } \\
\text { V16 }\end{array}$ \\
\hline 12 Feb 1622 & SMO & - & 0 & $\begin{array}{l}\text { Observation day not included in } \\
\text { V16 }\end{array}$ \\
\hline $28-30$ Apr 1624 & SMO & 1 & 2 & $\begin{array}{l}\text { Misinterpretation of the number of } \\
\text { groups in V16 }\end{array}$ \\
\hline 1-3 May 1624 & SMO & 1 & 3 & $\begin{array}{l}\text { Misinterpretation of the number of } \\
\text { groups in V16 }\end{array}$ \\
\hline 4 May 1624 & SMO & 1 & - & $\begin{array}{l}\text { Not possible to count the real } \\
\text { number of groups }\end{array}$ \\
\hline 14-17 Jan 1625 & SMO & 1 & 3 & $\begin{array}{l}\text { Misinterpretation of the number of } \\
\text { groups in V16 }\end{array}$ \\
\hline 18 Jan 1625 & SMO & 1 & 2 & $\begin{array}{l}\text { Misinterpretation of the number of } \\
\text { groups in V16 }\end{array}$ \\
\hline 12, 16, 17, 18, 21 Feb 1625 & SMO & 1 & - & $\begin{array}{l}\text { Not possible to count the real } \\
\text { number of groups }\end{array}$ \\
\hline 1 Jun 1625 & SMO & 1 & - & $\begin{array}{l}\text { Not possible to count the real } \\
\text { number of groups }\end{array}$ \\
\hline
\end{tabular}


Table 1 (Continued)

\begin{tabular}{|c|c|c|c|c|}
\hline Date & Observer & $\begin{array}{l}\text { Groups } \\
\text { (V16) }\end{array}$ & $\begin{array}{l}\text { Groups } \\
\text { (this work) }\end{array}$ & Comments \\
\hline 4, 5, 7 Jun 1625 & SMO & 1 & 3 & $\begin{array}{l}\text { Misinterpretation of the number of } \\
\text { groups in V16 }\end{array}$ \\
\hline 6,9 Jun 1625 & SMO & 1 & 2 & $\begin{array}{l}\text { Misinterpretation of the number of } \\
\text { groups in V16 }\end{array}$ \\
\hline $8,9,12,27,28,31$ Aug 1625 & SMO & 1 & - & $\begin{array}{l}\text { Not possible to count the real } \\
\text { number of groups }\end{array}$ \\
\hline $10,19,22,23$ Aug 1625 & SMO & 1 & 2 & $\begin{array}{l}\text { Misinterpretation of the number of } \\
\text { groups in V16 }\end{array}$ \\
\hline 18 Aug 1625 & SMO & 2 & 3 & $\begin{array}{l}\text { Misinterpretation of the number of } \\
\text { groups in V16 }\end{array}$ \\
\hline 1, 7, 8 Sep 1625 & SMO & 1 & - & $\begin{array}{l}\text { Not possible to count the real } \\
\text { number of groups }\end{array}$ \\
\hline 5,10 Oct 1625 & SMO & 8 & - & $\begin{array}{l}\text { Misinterpretation of observation } \\
\text { days in V16 }\end{array}$ \\
\hline 9 Oct 1625 & SMO & 4 & - & $\begin{array}{l}\text { Misinterpretation of observation } \\
\text { days in V16 }\end{array}$ \\
\hline 11 Oct 1625 & SMO & 9 & - & $\begin{array}{l}\text { Misinterpretation of observation } \\
\text { days in V16 }\end{array}$ \\
\hline $6,13-15,25-31$ Oct, 1 Nov 1625 & SMO & 1 & - & $\begin{array}{l}\text { Misinterpretation of observation } \\
\text { days in V16 }\end{array}$ \\
\hline \multicolumn{4}{|c|}{ Number of observation days in V16 (this work) assigned to Tarde } & $69(12)$ \\
\hline \multicolumn{4}{|c|}{$\begin{array}{l}\text { Number of observation days in V16 (this work) assigned to } \\
\text { Smogulecki }\end{array}$} & $82(52)$ \\
\hline
\end{tabular}

same observation day on 24 dates (Figure 4). Scheiner recorded a larger number of groups than Smogulecki on 10 days, the number of groups recorded by both observers was equal on 13 days and Smogulecki only observed more groups than Scheiner on 10 August 1625 (2 versus 1). Moreover, the averages of the number of recorded sunspot groups in the common observation days from Smogulecki's data and Scheiner's data are 2.5 and 3.1, respectively, i.e. Scheiner systematically recorded approximately a quarter more sunspot groups than Smogulecki. In addition, Schönberger recorded one group for the period 30 April to 3 May 1624 according to Carrasco et al. (2021), whereas Smogulecki recorded two groups on 30 April and three groups on the remaining dates.

Smogulecki observed a great sunspot on 2 and 3 February 1622. He recorded the following information on this sunspot (Smogulecki, 1626, pp. 47-48): "(English translation) The spot represented by the letters ' $\mathrm{X}$ ' and ' $\mathrm{Y}$ ' [see sunspot ' $\mathrm{Y}$ ' depicted between the sunspot drawings of Figure 1, bottom panel] was the only one observed in 1622. I could observe it here in Freiburg, but also Father Adam Tanner and Johann Baptist Cysat in Ingolstadt. It was certainly exceptional in size since its longitude was equivalent to one thirteenth of the solar diameter and its latitude, in its most voluminous part, was equivalent to one twenty-fourth of the solar diameter. Thanks to the tube, we have distinguished its inner shape on 2 (as it is represented in the image ' $\mathrm{Y}$ ') and 3 February 1622 (as it can be seen in the image ' $\mathrm{X}$ '). This spot had inside very black corpuscles as all those that generally take that form, and they were surrounded by a more tenuous matter. All these corpuscles recorded on the paper represented the figure of a single star or a very black spot that occupied the thirteenth part of the solar diameter. It moved below the Ecliptic, and during those days when it was close 

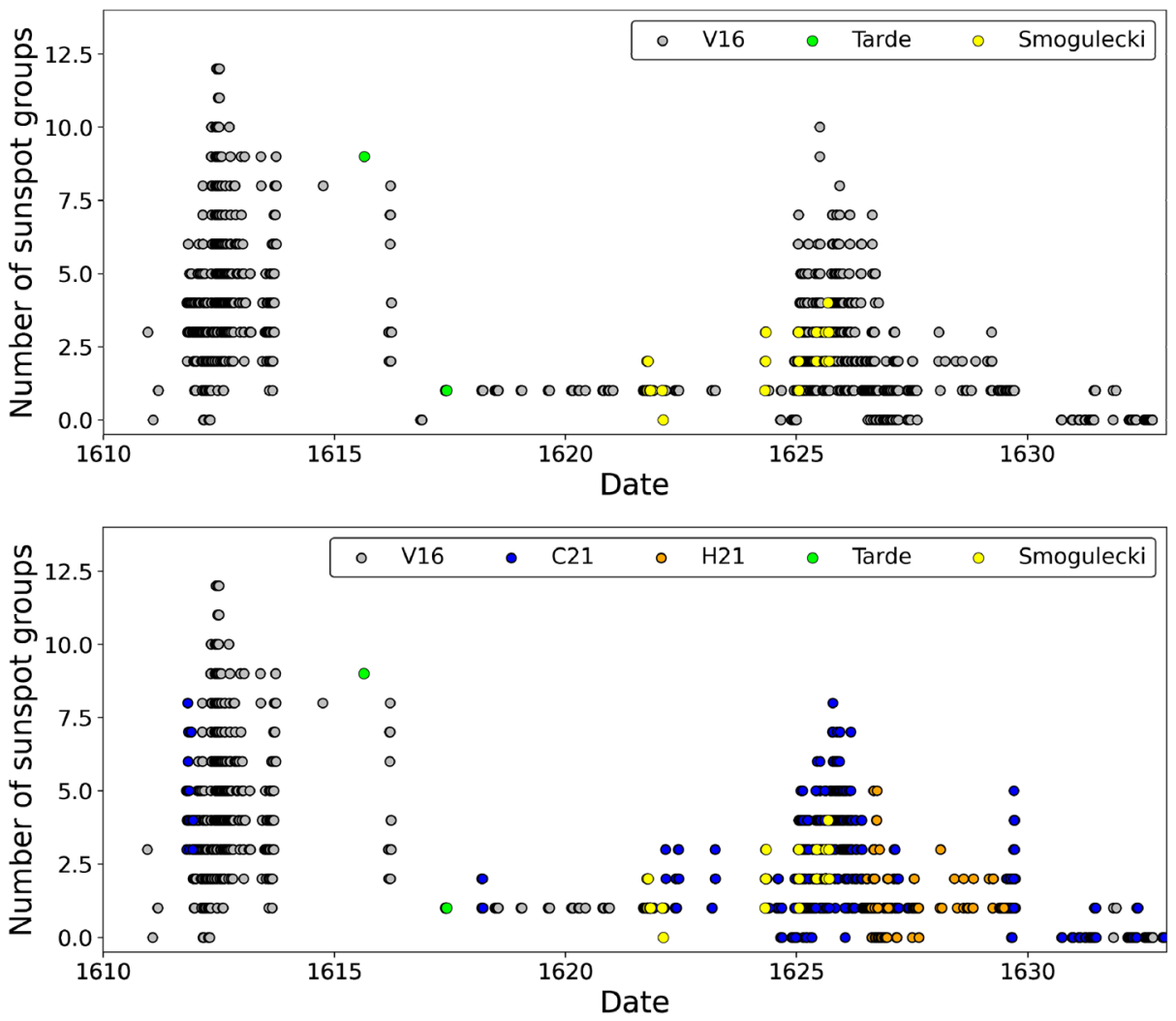

Figure 3 (Top panel) Daily number of sunspot groups included in V16 during the period 1610 - 1632 discarding records by Tarde and Smogulecki (grey). The number of groups recorded by Tarde and Smogulecki obtained in this work are represented by green and yellow, respectively. (Bottom panel) The same but including the corrections of Carrasco et al. (2021) (in blue) and Hayakawa et al. (2021) (in orange) for the number of recorded sunspot groups recorded during the period $1611-1632$.

Figure 4 Daily numbers of sunspot groups recorded by Smogulecki versus Scheiner. Different grey-scale represents the frequency of occurrence for each combination. Note that only common observation days have been used for this comparison. The diagonal line represents the slope equal to unity.

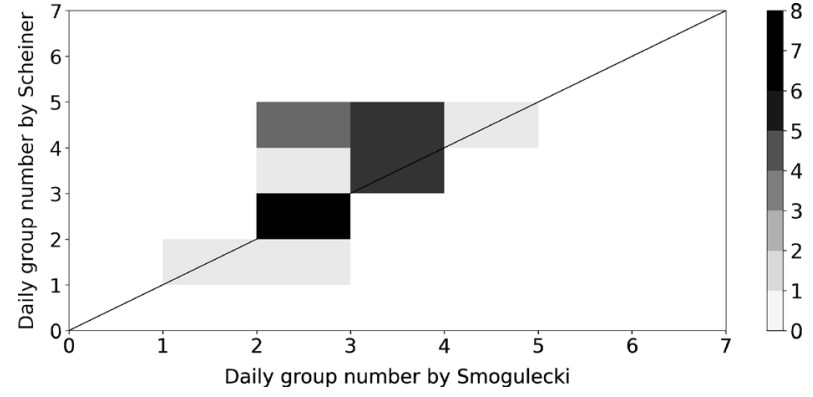

to the centre of the Sun, it was composed of seven tiny stars arranged in a ' $\mathrm{V}$ ' shape not surrounded by any cloud. This set reached a larger size the next day [February 3rd]; after that day, neither this spot nor the other large one could be seen because the sky was never clear at any time. On 12 February, when it was clear again, nothing else could be seen in the Sun with the tube." Thus, Smoguleki recorded a sunspot whose projected area on the solar 


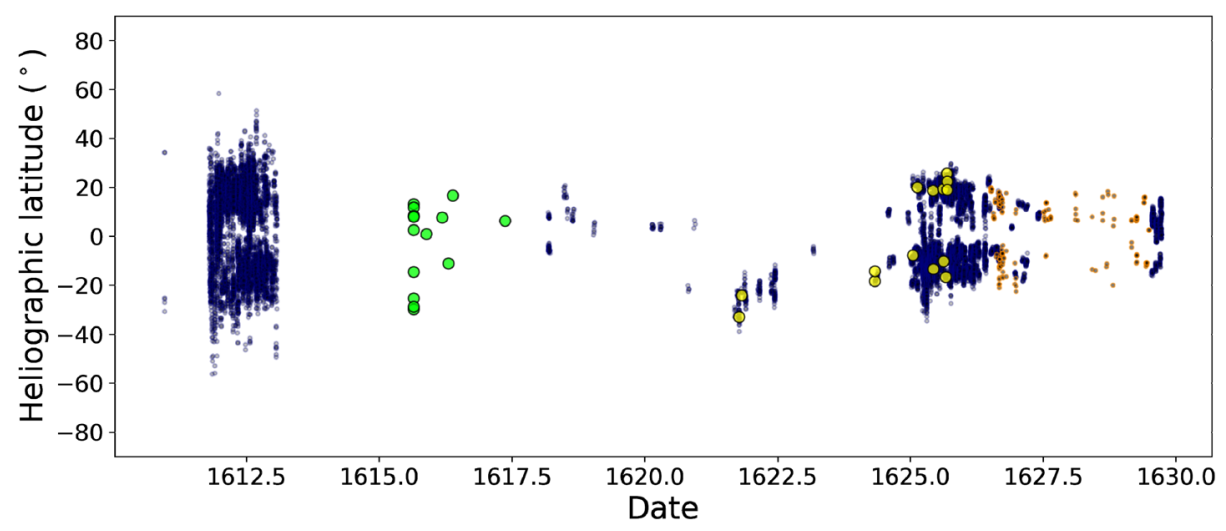

Figure 5 Sunspot positions computed for the period 1610 - 1630: i) in this work from Tarde's (green) and Smogulecki's (yellow) sunspot records, ii) those published by Muñoz-Jaramillo and Vaquero (2019) from sunspot observations made by Galileo, Scheiner, and other astronomers (small blue dots), and iii) those calculated by Hayakawa et al. (2021) from Mögling's records (small orange dots).

disc was approximately one-thirteenth in longitude of the solar diameter and one twentyfourth in latitude. If we assume an elliptical shape, we can estimate its projected area as $A=\pi a b$, where $a$ and $b$ are the semi-axes of the ellipse. Thus, this sunspot occupied a projected area of approximately 1600 millionths of the solar disc. Furthermore, candidate auroras were sighted in multiple European sites even down to Switzerland on 3 February 1622 (Abelinus, 1746, p. 619; Link, 1964, p. 514). Therefore, this great sunspot recorded in Smogulecki's account could have been responsible for the mid-latitude auroras and a plausible geomagnetic storm on 3 February 1622. It is known that the Sun can cause significant geomagnetic storms even during low solar activity (Garcia and Dryer, 1987; Hayakawa et al., 2020; Silverman and Hayakawa, 2021). As such, despite its location in the early rising phase of the solar cycle of the 1620 s, this active region could be associated with a significant geomagnetic storm, as found in parallel cases.

\section{Sunspot Positions from Tarde's and Smogulecki's Drawings}

We calculated the sunspot positions in Tarde's and Smogulecki's sunspot drawings. In this study, we used Soonspot, a program created to calculate sunspot positions and areas (Galaviz et al., 2019). Areas were not computed in this work because both observers represented the sunspot groups as simple dots (see Figure 1).

We defined the sunspot groups in Tarde's and Smogulecki's records for the period $1615-1625$ and calculated the latitudinal average of each group over time. Since the observation by Tarde on 25 August 1615 was made at noon, we assume that the orientation of the drawing is based on the Earth's axes. Moreover, we assume that the orientation of both Tarde's and Smogulecki's sunspot drawings are according to erect images. All latitudes obtained in this work are represented by green (Tarde) and yellow (Smogulecki) in Figure 5, and they are compared with the sunspot positions obtained in other studies. Small blue dots are the sunspot latitudes published by Muñoz-Jaramillo and Vaquero (2019) from the sunspot positions recorded by other observers at that time. In this study, the positions computed by Arlt et al. (2016) from Scheiner's records, Vokhmyanin and Zolotova (2018a,b) for Galileo's and Gassendi's drawings, and Carrasco et al. (2019) for Malapert's observations 
were included. Moreover, Hayakawa et al. (2021) calculated the sunspot positions from Mogling's drawings. Thus, we calculated the latitudes for 14 sunspot groups recorded by Tarde and another 14 groups using Smogulecki's records. Nine of the 14 sunspot groups in Tarde's records were in the northern hemisphere and five in the southern hemisphere. The group furthest from the solar Equator was recorded at $-29.8^{\circ}$, and six groups appeared at latitudes between $-10^{\circ}$ and $+10^{\circ}$, according to Tarde's records. The sunspot positions computed in this work from Tarde's observations are the only calculations of the sunspot positions available in that period. Regarding Smogulecki's data, eight groups were recorded by this observer in the southern hemisphere and six in the northern hemisphere. The group with the highest latitude was located at $-33.0^{\circ}$, and only one group was recorded near the solar Equator between $-10^{\circ}$ and $+10^{\circ}$. The latitudes calculated in this work from Smogulecki's records are similar to those computed by Arlt et al. (2016) from Scheiner's drawings on the same dates, which are depicted by small blue dots in Figure 5.

\section{Conclusions}

We have revised the sunspot observations made by Tarde in 1615-1617 and Smogulecki in $1621-1625$. These astronomers published their observations in the books Borbonia Sidera and Sol illustratus, respectively. In their documentary sources, these observers recorded both sunspot drawings and textual reports to explain their observations. In their drawings, Tarde and Smogulecki sometimes recorded only some of the groups that they observed on the same day. This has led to misinterpretations of these records in existing databases (Hoyt and Schatten, 1998; Vaquero et al., 2016). In this study, we identified these problems and provided a revised group counting. We acknowledge that the number of observations made by these observers does not have a large observational coverage, but they are important because most of their records are the only ones available of sunspot records on those observing dates.

We compared Smogulecki's sunspot observations to those of other observers at that time. For example, we found that Scheiner recorded an average of approximately a quarter more groups than Smogulecki. Smogulecki also recorded an exceptionally large sunspot group on $2-3$ February 1622. Based on his descriptions, we estimated its area to be 1600 millionths of the projected area of the solar disc. In addition, we calculated the sunspot latitude of the sunspot groups in Tarde and Smogulecki's records. No sunspot latitude is available from previous reconstructions of the butterfly diagram fot the years when Tarde conducted observations. The latitudes computed from Smogulecki's data were similar to those obtained by other observers on the same observation days. The group counting and sunspot positions obtained in this work and the English translation from the original texts will be publicly available on the website of the Historical Archive of Sunspot Observation: haso.unex.es.

Acknowledgements This research was supported by the Economy and Infrastructure Counselling of the Junta of Extremadura through grant GR18097 (co-financed by the European Regional Development Fund) and by the Ministerio de Economía y Competitividad of the Spanish Government (CGL2017-87917-P). H. Hayakawa grateful thanks the financial supports of JSPS Grant-in-Aids JP15H05812, JP20K20918, JP20H05643, and JP21K13957, JSPS Overseas Challenge Program for Young Researchers, JSPS Overseas Challenge Program for Young Researchers, the FY2020 YLC collaborating research fund, and the ISEE director's leadership fund for FY2021 of Nagoya University, and the research grants for Mission Research on Sustainable Humanosphere from Research Institute for Sustainable Humanosphere (RISH) of Kyoto University. H. Hayakawa's contributions have been conducted as a part of efforts in the ISWAT-COSPAR S1-01 team. The authors have benefited from the participation in the ISSI workshops led by M.J. Owens and F. Clette on the calibration of the sunspot number.

Funding Note Open Access funding provided thanks to the CRUE-CSIC agreement with Springer Nature. 


\section{Declarations}

Disclosure of Potential Conflicts of Interest The authors declare that they have no conflicts of interest.

Open Access This article is licensed under a Creative Commons Attribution 4.0 International License, which permits use, sharing, adaptation, distribution and reproduction in any medium or format, as long as you give appropriate credit to the original author(s) and the source, provide a link to the Creative Commons licence, and indicate if changes were made. The images or other third party material in this article are included in the article's Creative Commons licence, unless indicated otherwise in a credit line to the material. If material is not included in the article's Creative Commons licence and your intended use is not permitted by statutory regulation or exceeds the permitted use, you will need to obtain permission directly from the copyright holder. To view a copy of this licence, visit http://creativecommons.org/licenses/by/4.0/.

\section{References}

Abelinus, J.P.: 1746, Theatrum Europaeum, Oder Außführliche und Warhafftige Beschreibung aller und jeder denckwürdiger Geschichten, Merian, Franckfurt.

Arlt, R., Vaquero, J.M.: 2020, Historical sunspot records. Liv. Rev. Solar Phys. 17, 1. DOI.

Arlt, R., Senthamizh Pavai, V., Schmiel, C., Spada, F.: 2016, Sunspot positions, areas, and group tilt angles for 1611 - 1631 from observations by Christoph Scheiner. Astron. Astrophys. 595, A104. DOI.

Baumgartner, F.J.: 1987, Sunspots or Sun's planets - Jean Tarde and the sunspot controversy of the early 17th-century. J. Hist. Astron. 18, 44. DOI.

Cardarelli, F.: 2003, Encyclopaedia of Scientific Units, Weights and Measures, Springer, London. DOI.

Carrasco, V.M.S., Gallego, M.C., Vaquero, J.M.: 2020, Number of sunspot groups from the Galileo-Scheiner controversy revisited. Mon. Not. Roy. Astron. Soc. 496, 2482. DOI.

Carrasco, V.M.S., Gallego, M.C., Villalba Álvarez, J., Vaquero, J.M.: 2019, Sunspot observations by Charles Malapert during the period 1618 - 1626: a key data set to understand solar activity before the Maunder minimum. Mon. Not. Roy. Astron. Soc. 488, 3884. DOI.

Carrasco, V.M.S., Muñoz-Jaramillo, A., Gallego, M.C., Vaquero, J.M.: 2021, Revisiting Christoph Scheiner's sunspot records: a new perspective on solar activity of the early telescopic era. Astrophys. J. submitted.

Clette, F., Lefèvre, L.: 2016, The new sunspot number: assembling all corrections. Solar Phys. $291,2629$. DOI.

Clette, F., Svalgaard, L., Vaquero, J.M., Cliver, E.W.: 2014, Revisiting the sunspot number. A 400-year perspective on the solar cycle. Space Sci. Rev. 186, 35. DOI.

Dujarric-Descombes, A.: 1971 Recherches sur les historiens du Perigord au XVIIe siecle, Slatkine, Geneva.

Galaviz, P., Carrasco, V.M.S., Sánchez-Bajo, F., Gallego, M.C., Vaquero, J.M.: 2019, Soonspot: a software to determine areas and sunspot positions. Solar Phys. 295, 17. DOI.

Galilei, G., Scheiner, C.: 2010, On Sunspots. Reeves, E., Van Helden, A. (eds.):. University of Chicago Press, Chicago.

Garcia, H.A., Dryer, M.: 1987, The solar flares of February 1986 and the ensuing intense geomagnetic storm. Solar Phys. 109, 119. DOI.

Hayakawa, H., Tamazawa, H., Ebihara, Y., Miyahara, H., Kawamura, A.D., Aoyama, T., Isobe, H.: 2017, Records of sunspots and aurora candidates in the Chinese official histories of the Yuán and Míng dynasties during 1261-1644. Publ. Astron. Soc. Japan 69, 65. DOI.

Hayakawa, H., Ribeiro, P., Vaquero, J.M., Gallego, M.C., Knipp, D.J., Mekhaldi, F., et al.: 2020, The extreme space weather event in 1903 October/November: an outburst from the quiet Sun. Astrophys. J. Lett. 897, L10. DOI.

Hayakawa, H., Iju, T., Murata, K., Besser, B.P.: 2021, Daniel Mögling's sunspot observations in 1626-1629: a manuscript reference for the solar activity before the Maunder Minimum. Astrophys. J. 909, 194. DOI.

Hoyt, D.V., Schatten, K.H.: 1998, Group sunspot numbers: a new solar activity reconstruction. Solar Phys. 179, 189. DOI.

Kosibowiez, K.: 1929, Un missionnaire polonais oublié: le Père Jean Nicolas Smogulecki S.J., missionnaire en Chine au XVIIème siècle. Rev. Hist. Missions 22, 335.

Link, F.: 1964, Observations et catalogues des aurores boreales apparues en occident de 1601 a 1700 . Geofys. Sbor. 212, 501.

Muñoz-Jaramillo, A., Vaquero, J.M.: 2019, Visualization of the challenges and limitations of the long-term sunspot number record. Nat. Astron. 3, 205. DOI.

Neuhäuser, R., Neuhäuser, D.L.: 2016, Sunspot numbers based on historic records in the 1610s: early telescopic observations by Simon Marius and others. Astron. Nachr. 337, 581. DOI. 
Roegel, D.: 2011, A reconstruction of Smogulecki and Xue's table of logarithms of numbers (ca. 1653. Research Report, hal-00654451, INRIA: hal.inria.fr/hal-00654438.

Saridakis, V.: 2014, Tarde, Jean. In: Hockey, T., Trimble, V., Williams, T.R., Bracher, K., Jarrell, R.A., Marché, J.D., Palmeri, J., Green, D.W.E. (eds.) Biographical Encyclopedia of Astronomers, Springer, New York, 2126. DOI.

Scheiner, C.: 1630, Rosa Ursina Sive Sol, Andrea Fei, Bracciano.

Scheiner, C.: 1651, Prodromus pro sole mobili et terra stabili contra Galilaeum a Galileis, Societatis Iesu, Rome.

Silverman, S.M., Hayakawa, H.: 2021, The Dalton minimum and John Dalton's auroral observations. J. Space Weather Space Clim. 11, 17. DOI.

Smogulecki, J.: 1626 Sol illustratus, Theodorus Meyer, Friburg.

Tarde, J.: 1620, Borbonia sidera, Jean Gesselin, Paris.

Tarde, J.: 1627, Les astres de Borbon et apologie pour le Soleil, Jean Gesselin, Paris.

Vaquero, J.M., Vázquez, M.: 2009, The Sun Recorded Through History, Springer, Berlin.

Vaquero, J.M., Svalgaard, L., Carrasco, V.M.S., Clette, F., Lefèvre, L., Gallego, M.C., Arlt, R., Aparicio, A.J.P., Richard, J.-G., Howe, R.: 2016, A revised collection of sunspot group numbers. Solar Phys. 291, 3061. DOI.

Vokhmyanin, M.V., Zolotova, N.V.: 2018a, Sunspot positions and areas from observations by Galileo Galilei. Solar Phys. 293, 31. DOI.

Vokhmyanin, M.V., Zolotova, N.V.: 2018b, Sunspot positions and areas from observations by Pierre Gassendi. Solar Phys. 293, 150. DOI.

Vokhmyanin, M.V., Arlt, R., Zolotova, N.V.: 2020, Sunspot positions and areas from observations by Thomas Harriot. Solar Phys. 295, 39. DOI.

Vokhmyanin, M.V., Arlt, R., Zolotova, N.V.: 2021, Sunspot positions and areas from observations by Cigoli, Galilei, Cologna, Scheiner, and Colonna in 1612 - 1614. Solar Phys. 296, 4. DOI.

Willis, D.M., Wilkinson, J., Scott, C.J., Wild, M.N., Stephenson, F.R., Hayakawa, H., Brugge, R., Macdonald, L.T.: 2018, Sunspot observations on 10 and 11 February 1917: a case study in collating known and previously undocumented records. Space Weather 16, 1740. DOI.

Witkowska, S.: 2009, Jan Mikołaj Smogulecki, the man who brought logarithms to China. In: Majewicz, A.F., Gaca, M., Majewicz, E. (eds.) Linguistic and Oriental Studies from Poznań 9, Wydawnictwo Naukowe, Poznań, 241.

Wolf, R.: 1859a, Mitth. uber die Sonnenflecken 7, 173.

Wolf, R.: 1859b, Mitth. uber die Sonnenflecken 8, 204.

Yau, K.K.C., Stephenson, F.R.: 1988, A revised catalogue of Far Eastern 353 observations of sunspots (165 BC to AD 1918). Quart. J. Roy. Astron. Soc. 29, 175.

Publisher's Note Springer Nature remains neutral with regard to jurisdictional claims in published maps and institutional affiliations. 